\title{
COMPARISON OF WALKABILITY IN DIFFERENT URBAN DISTRICTS USING SPACE SYNTAX
}

\author{
Farnoosh ROOZKHOSH (D) ${ }^{*}$, Mehrnaz MOLAVI, Aliakbar SALARIPOUR \\ Department of Urban Planning and Design, University of Guilan, Guilan, Iran \\ Received 14 November 2018; accepted 10 June 2019
}

\begin{abstract}
The expansion of cities and increasing car traffic have brought problems such as increased greenhouse emission, noise pollution, and access problems that makes sustainable urban development one of the most significant concerns of urban governors. Obviously, the utilization of public transportation and walkability is one of the highly significant aspects of sustainable development. In an effort for the recognition of urban districts of Bojnourd, the current article compares the extent of walkability in each district. To investigate the walkability index using the opinions of experts and scholars 4 criteria and 22 sub-criteria were taken into consideration. In this regard, the ANP approach was also applied to improve decision making and grading the importance of criteria; districts were finally graded using the TOPSIS model concerning walkability. In the present study as an applied one, field surveys, questionnaires, library studies, and documents were the data collection tools. The findings revealed that the old district (central), have the highest walkability potential in comparison to medial, and the new development districts respectively. Since the old district has the highest amount of mixed land uses, passage connectivity, passage integration, public transport, and so forth, it can be concluded that walkability is closely related to the mentioned factors.
\end{abstract}

Keywords: walkability, space syntax, TOPSIS, ANP, urban district, mix landuse.

\section{Introduction}

One of the challenges urban and transport planners are dealing with is negligence in providing the places appropriate for walking which could attract pedestrians in cities. Beneficial for the health of cities and citizens, walking demands more attention of urban managers. It encompasses both the physical health of citizens and many environmental advantages, for instance, reduction of the fossil fuels use and consequently air pollution, as well as noise and visual pollution. This method is meanwhile quite economical and costs less than public transportation.

In new districts more dependence of humans on cars has led to the dominance of driving over walking, which itself has caused the neglect in walking and in providing facilities that motivate walking.

Since changing to a capital city of the North Khorasan province in 2004, Bojnourd has shown a rapid growth and many village-city immigrations in recent years, which has begot the expansion of suburbs and the emergence of new developments to accommodate the immigrants. Different types of urban districts in Bojnourd City including old, medial, and new are suffering from the issue of pedes- trian-driver connection network and consequently many problems such as the access weakness, noise, irregularity, air pollution, reduced safety level for pedestrians and drivers, and no access to public transportation have emerged. In the other word, the disruption of daily life due to motor vehicle traffic problems is evident in the city. The purpose of this article is to analyze the walkability in these three types of districts, and ultimately to determine the superior district concerning walkability.

\section{Research methodology}

In this study, the existing districts of Bojnourd were firstly identified and a part of each District was studied as a sample. In order to investigate the Walkability Index applying the opinions of the experts and scholars, 4 criteria and 22 sub-criteria were considered; the criteria were asked from 70 people in the form of a questionnaire in each of the neighborhoods (totally 210 people) combined with an interview. The Likert scale questionnaire consisted of 27 questions. Integration criteria, connectivity, selection, and so forth were also extracted based on the theory of Space Syntax and according to the key map of the current

*Corresponding author. E-mail: farnoosh.roozkhosh@yahoo.com 
situation in the studied districts. The other intended criteria were also investigated by calculating the mixed land uses and examining the 11 considered uses through Shannon Entropy, calculating the density of the intersections, the length of the streets and so on. After that, using the experts' opinion, applying the Analytic Network Process "ANP," and utilizing the Super Decisions software, the criteria were weighted. Using the TOPSIS model, then, the acquired weights resulted from the ranking of criteria in ANP and the extracted data of the above-mentioned methods were combined and the final weight of each District was calculated in terms of walkability.

\section{Literature review}

In the last two decades, valuable research has been conducted on walkability in cities. Moeini (2007), Soltani and Pirouzi (2013), and Mohammadi and Hajizadeh (2016) have respectively researched on the relationship between fossil fuels consumption and automobile with walkability, the relationship between environmental pollution and safety and security of pedestrians regarding walkability, and the ranking of urban neighborhoods based on the walkability model. Obviously, less attention has been paid to investigate the walkability potential in various types of urban districts.

For instance, Hung et al. in their study in 2010, with the topic of walkability calibration in Hong Kong, as a comprehensive study attempted to help planners to be aware of the walkability conditions in the city, and to identify the deficiencies connected with the pedestrian areas. In this research, the Global Walkability Index (GWI) and the Asian Development Bank/Clean Air for Asian Cities (CAI-ASIA) have been used after localizing them with the conditions of Hong Kong. The study reveals that merely 50 percent of the people were satisfied with the current situation, and dissatisfied people have emphasized on the necessity of street lighting, cleanliness, shading and broadening pedestrian areas, reducing traffic and speed in the streets, removing barriers to pedestrians and increasing signs in intersections (Soltani \& Pirouzi, 2013).

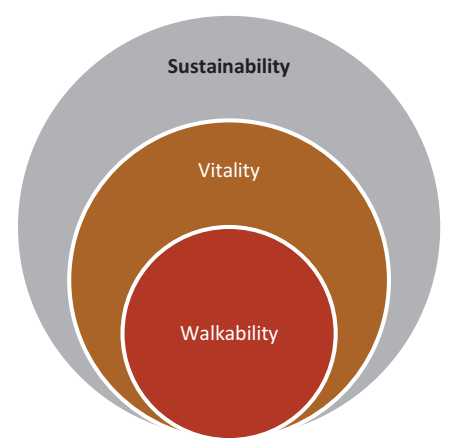

Figure 1 . The relationship between vitality and walking (source: Shamsuddin et al., 2012, p. 169)

\section{Concepts and definitions}

\subsection{Walkability}

Walkability as a component of vitality plays a fundamental role in promoting a sustainable environment and creating a lively place, Figure 1. Reducing noise and air pollution, walkability encourages residents to walk (Shamsuddin et al., 2012, p. 169).

A place is walkable when its inhabitants at different ages having different levels of ability would be able to feel the attractiveness and desirability, comfort and security while walking not only in leisure time but also in their daily commute (Chapman, 2004, p. 156) (Figure 2).

\subsection{Walkability conceptual framework}

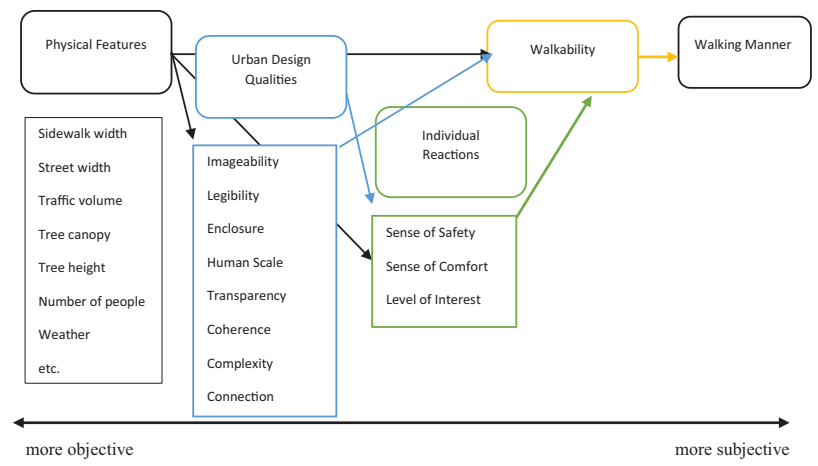

Figure 2. Walkability conceptual framework (source: Ewing et al., 2006, p. 225)

\subsection{Walking potential}

Lack of suitable and attractive passages is one of the reasons that make people not interested in walking. Concerning urban design, urban amenities and furniture, and visual features, the existing sidewalks are not suitable. Therefore, it is essential to carry out research that addresses the problems of passages from this perspective and provides solutions for their improvement. The first step in this regard is to determine the spatial indicators effective in encouraging citizens to walk and provide an appropriate analytical tool for measuring the appropriateness of the existing sidewalks based on these indicators. This concept called as the potential of walking, is defined as the suitability of a specific walking environment (Lwin \& Murayama, 2010, p. 412). The walking potential index is described as measuring the effective urban design features to promote the use of non-motorized transport including walking and cycling as alternatives for driving (Rattan et al., 2012, p. 31). Walking potential is an assessment scale of a walking environment attractiveness. In this regard, the quality of pedestrian facilities, road conditions, land use patterns, social protection, safety, and walking comfort should be taken into consideration. Walking potential is a fundamental concept in sustainable urban design (Raja et al., 2013, p. 590). 
Pedestrians have to cross the street. Where the pedestrian line is located, there is a lower speed and less vehicle vulnerability. This matter, where there is high speed or flow, can lead to delays or risks for pedestrians. In recent decades, several factors have reduced pedestrian injuries, which are as follows: better designed vehicles, the effective speed management, traffic routing, and walking simplification (Martin, 2006, p. 1).

\subsection{The significance of walking}

Sidewalks have specific social and physical structures. Today, many efforts are being made at different levels of urban planning to encourage and facilitate walking on sidewalks, with great contributions of governments and municipalities, so that many cities have been developing plans and outlooks for the development of pedestrian networks at different time scales, and in particular with the outlook of the 21st century (Nasiri, 2012, p. 14). However, in the cities currently dominated in all respects by vehicles, walking is underestimated, and pedestrians are always at risk of physical and financial harm. In other words, walking from the two main aspects, (as a pillar of the intra-urban transport system and as a space for communication and social encounters) has not only been neglected, but now has little to do with it, so that pedestrians find their rights trampled (Rafieian et al., 2011, p. 4). Accidents and lack of safety are of the most important issues, and investment in the pavement network can be very effective in reducing accidents. In 2008, 7491 pedestrians were killed in European accidents, which reveal about 20.4 percent of the total number of deaths in accidents. By the end of the first decade of the twentyfirst century, pedestrian accidents have fallen by 25.2 percent comparing to the previous decade, and the total number of accidents has dropped by about 30 percent. The replacement of road safety equipment has helped to reduce the number of pedestrian accidents in the last 10 years (Brandstaetter et al., 2010, p. 1). Despite the risks, it is important to consider the benefits of walking and walkability, including increasing early mobility, saving consumer spending, saving all costs (reducing external costs), efficient land use, building a livable community, fitness and public health, economic development and supporting justice objectives (Litman, 2017, p. 1).

Waldock mentions the important advantages of sidewalks:

1 - Connection (The role of pedestrian networks in having proper access to the destination);

2 - Flexibility (Has it the appropriate conditions in the neighborhoods, it can create an environment that meets the needs of the human body);

3 - Comfort (Facilitate street crossing for pedestrians);

4 - Being joyful;

5 - Clarity and transparency (Waldock, 2012, p. 64).

\subsection{Case study}

In the north of Khorasan, there are some medium and small plains that sedimentation in them creates suitable agricultural areas and provides the basis for the formation and expansion of cities such as Bojnourd. Bojnourd is located $250 \mathrm{~km}$ northwest of Mashhad and is located almost in the geographical center of the province (Naqsh,e JahanPars consulting engineer, 2011). According to the census in 2016, the city has a population of about 324,083 people (Iranian Statistical Center, 2016). In addition, the highest percentage of the city area is residential that is $27.5 \%$ of its area $(785.6 \mathrm{hc})$. The lowest percentage is urban facilities and equipment, which is 8.1 percent of the city area (50.1 hectares) (Naqsh,e Jahan-Pars consulting engineer, 2011).

\subsection{Studied indexes of walkability}

According to reliable scientific studies and field experts, 4 criteria and 22 sub-criteria were considered for studying and measuring walkability (Table 1).

\subsubsection{How to calculate walkability indexes}

To quantitatively calculate the given sub-criteria, some indicators such as availability, accessibility, and quality of public transportation, abandoned buildings, passageways lighting, non-disturbance, access to urban furniture and its quality, adequate green space, waste collection, nondisposal of surface water, unpleasant smell, leisure time, street art activities and access to sports and recreational facilities were prepared and studied through a questionnaire. Positiveness and negativeness of sub-criteria have been included in the table.

\subsection{Mixed land use index}

Considering the data, the studied uses to determine the mixed land uses in any District includes 11 ones: administrative, commercial, residential, commercial-residential, globetrotting, religious, educational, facilities and equipment, social-cultural, parking, and recreational (including green space and parks). At this stage, first, the GIS map of each of the districts was separated from the total area of the city using Clip instruction and then 11 given uses were analyzed in each District.

In order to calculate the mixed land uses in each District, the Shannon Entropy formulation was used as the equation1 shows:

Mixed Land use $=-\frac{\sum_{j=1}^{k}\left(p_{j}{ }^{\star} \ln \left(p_{j}\right)\right)}{\ln \left(k_{i}\right)}$ For $k_{i}>1$.

\subsubsection{Mixed land use rate}

In this equation $p_{j}$ is equal to the proportion of the area of use $j$ to total area of the region $i$; $k_{i}$ is equal to the number of different uses in the region $i$. Also is $k_{i}$ equal to 1 , the value of this index is considered zero. In this research, $k_{i}$ is equal to eleven. 
Table 1. Walkability criteria and sub-criteria (source: authors)

\begin{tabular}{|c|c|c|c|}
\hline Title: & Criteria & Sub-Criteria & Type of Criteria \\
\hline \multirow{22}{*}{$\begin{array}{l}\text { Walkability } \\
\text { Potential }\end{array}$} & \multirow[t]{7}{*}{ Transportation } & Access to Public Transportation & Positive \\
\hline & & How to Access to Public Transportation & Positive \\
\hline & & Public Transportation Quality & Positive \\
\hline & & Connectivity & Positive \\
\hline & & Integration & Positive \\
\hline & & Intersection Density & Positive \\
\hline & & Street Length Density & Positive \\
\hline & \multirow[t]{2}{*}{ Density } & Population Density & Positive \\
\hline & & Building Density & Positive \\
\hline & \multirow[t]{3}{*}{ Social Security } & Abandoned Buildings & Negative \\
\hline & & Passageways Lighting & Positive \\
\hline & & No Disturbance & Positive \\
\hline & \multirow[t]{10}{*}{ Quality of Urban Environment } & Access to Urban Furniture & Positive \\
\hline & & Quality of Urban Furniture & Positive \\
\hline & & Enough Green Space & Positive \\
\hline & & Rubbish Collection & Positive \\
\hline & & Failure to Dispose Surface Water & Negative \\
\hline & & Unpleasant Odor & Negative \\
\hline & & Spending Leisure Time & Positive \\
\hline & & Street Art Activities & Positive \\
\hline & & Access to Sports and Recreational Facilities & Positive \\
\hline & & Mixing Use & Positive \\
\hline
\end{tabular}

\subsection{Connectivity and integration index}

To calculate these two indicators, the theory of Space Syntax and Ucl Depthmap software has been applied. To implement the model, first, convex space and axial map of the studied districts are drawn in the Auto CAD software and then are transmitted to Ucl Depthmap software. The software studies and evaluates the maximum, minimum, and average of the integration and connectivity in the old, the medial, and the new districts. The output of this software is used to measure walkability. Since the connectivity index of passages measures the number of splits that are related to a space without an intermediary, the greater the connectivity is, the greater the selectivity and attendance of the people would be, so it will have a positive impact on the walkability. In addition, the integration index, called accessibility, is a variable that refers to how a space is connected with other spaces around it. This index is also a key parameter that leads to an understanding of the relationships between users and urban space (Dettlafe, 2014, p. 288). So, the more the integration parameter is, the greater the willingness of the inhabitants to walk would be.

\subsection{Intersection density index}

The purpose of this index is to study the intersections density in the three studied districts. The following formula has been used to calculate this index:

$$
\text { Intersection Density }=\frac{\text { Intersection Number }}{\text { Area }} \text {. }
$$

In this equation, Intersection Number equals to the number of street intersections and Area is equal to the area of the region in the studied districts. This parameter is studied since the intersection of the streets increases the walking potential.

\subsection{Street length density index}

The purpose of this indicator is to investigate the length of street density in the three studied districts. The following formula has been used to calculate this index:

$$
\text { Street Length Density }=\frac{\text { Length of Streets }}{\text { Area }} \text {. }
$$

In this equation, Length of Streets is equal to the total length of the streets in the studied districts; this parameter is studied because of the weakness of the streets intersection density index in non-intersecting areas. It means there might be a place where the streets do not intersect, while the existence of the same long streets will increase the level of access. If the streets intersection density index is just reviewed, these streets will be deleted. By combining these two parameters, a more appropriate index can be created. The final point is the street length density index is 
somehow an indication of the appropriate number of passages (SabzaliYamghani \& Alesheikh, 2015, p. 163).

\subsection{Population Density Index}

The purpose of this indicator is to study the population density in the three studied districts. The following formula has been used to calculate this index:

$$
\text { Population Density }=\frac{\text { Population }}{\text { Area }} \text {. }
$$

In this equation, Population is equal to the population of the studied districts. Since high population density increases the craving for walking, and this point makes people feel safe, this parameter is studied. Research has also shown that areas with high population density are commonly found in urban centers, which increase the short trips (SabzaliYamghani \& Alesheikh, 2015, p. 163).

\subsection{Building density index}

The purpose of this index is to study the building density in the three studied districts. The following formula has been used to calculate this index:

$$
\text { Building Density }=\frac{\text { Gross Infrastructure }}{\text { Area }} \text {. }
$$

In this equation, gross infrastructure is equal to the infrastructure of the entire existing floors and buildings in the districts under the study. This parameter is examined, since with increasing building density, the number of households in the region has also increased, and this will increase the traffic.

\subsection{The process of ANP network analysis}

The process of ANP network analysis is one of the multicriteria decision making techniques, which was recommended as an appropriate alternative for hierarchical analysis process in 1996 by Saati. This model can control and manage the interdependency among the elements and within the network (Lee \& Wu, 2005, p. 3).

At this stage, using the comments of ten experts for each region, using the ANP method and Super Decisions software, first, the relationship among the criteria is determined (this relationship can exist among the sub-criteria of one criterion with each other, or with sub-criteria of the other criteria, unidirectional or bidirectional). Then their paired comparison is done and the final weight is estimated. An important point in calculating the weight of the criteria using the ANP method is the compatibility factor. This coefficient must be less than 0.1 to be accepted. In the present study, also the Compatibility Coefficient has been less than 0.1 in all the paired comparisons.

\subsection{Using the TOPSIS method to achieve superior district in terms of walkability}

One of the multi-index decision-making models capable of solving many decision-making issues for managers and planners is the TOPSIS model. This model was first introduced in 1981 by Huang and Yun, with improvements over time opening up its place as one of the best and most accurate multi-index decision making methods among managers and planners. The theoretical foundations of this technique are firstly finding the positive ideals (the best form) and the negative ideals (the worst form) for each of the indicators by a series of techniques and then calculating the distance between each option of the positive and negative ideals. The selected option is the one with the least distance from the positive ideals and the greatest distance from the negative ideals (Pourmohammadi \& Koushaneh, 2014, p. 42).

In this study, the TOPSIS method was used for the final ranking of the districts in terms of walkability.

\section{Selection of the studied districts}

\subsection{Identification of the districts in Bojnourd}

In order to sort and classify urban districts, often more than ten factors and characteristics are used to differentiate urban districts. These factors areformation time, rate of formation, connection networks, population density, urbanization rate, land use composition, environmental balance, establishment of urban functions, physical coherence, coordination of the constituent elements of the District and the building density (Haeri, 1992, p. 34). In this study, using the selection and combination of several factors from among the above-mentioned factors, which are the base of the analogy and separation of the districts, and the maps related to the historical evolution of city growth, the physical body of Bojnourd is divided into the three districts of old, medial, and outer (Figure 3). Each of these districts has characteristics, problems and issues, facilities and limitations for future development of the city (Ziari et al., 2012, p. 224).

\subsection{Selecting the scope of the study in each of the existing districts}

After recognizing the types of urban districts in Bojnourd, three regions were selected from each of the different types of old, medial, and outer (new) districts (Figure 4).

\section{Calculating the parameters}

\subsection{Calculating the mixed land use in the three studied districts}

The total area of the old district is equal to 461667.94 , the medial district is 528684.19, and the new developed district is 827015.52 sq. $\mathrm{m}$. According to the land use map and using GIS software, the allocated levels to each of the intended uses have been obtained (Table 2).

According to the Shannon Entropy formula, the results of calculating the mixed land use rate of the three studied districts (Table 3) are as follows: 
Guide

Old Texture

Middle Texture

New Texture

Scale: 1:50000

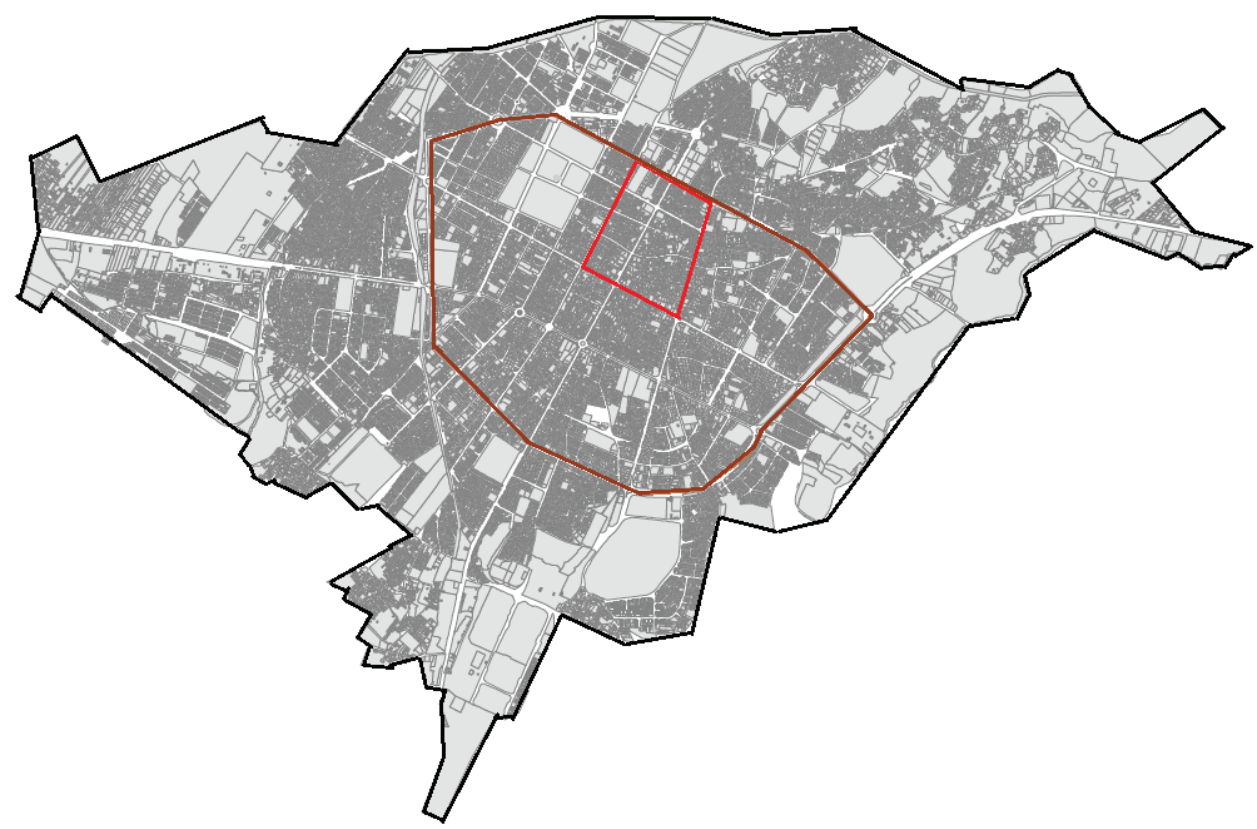

Figure 3. Division of districts in Bojnourd city (source: Ziari et al., 2012, p. 227)

Guide

Old Texture

Middle Texture

New Texture

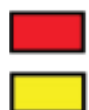

Scale: 1:50000

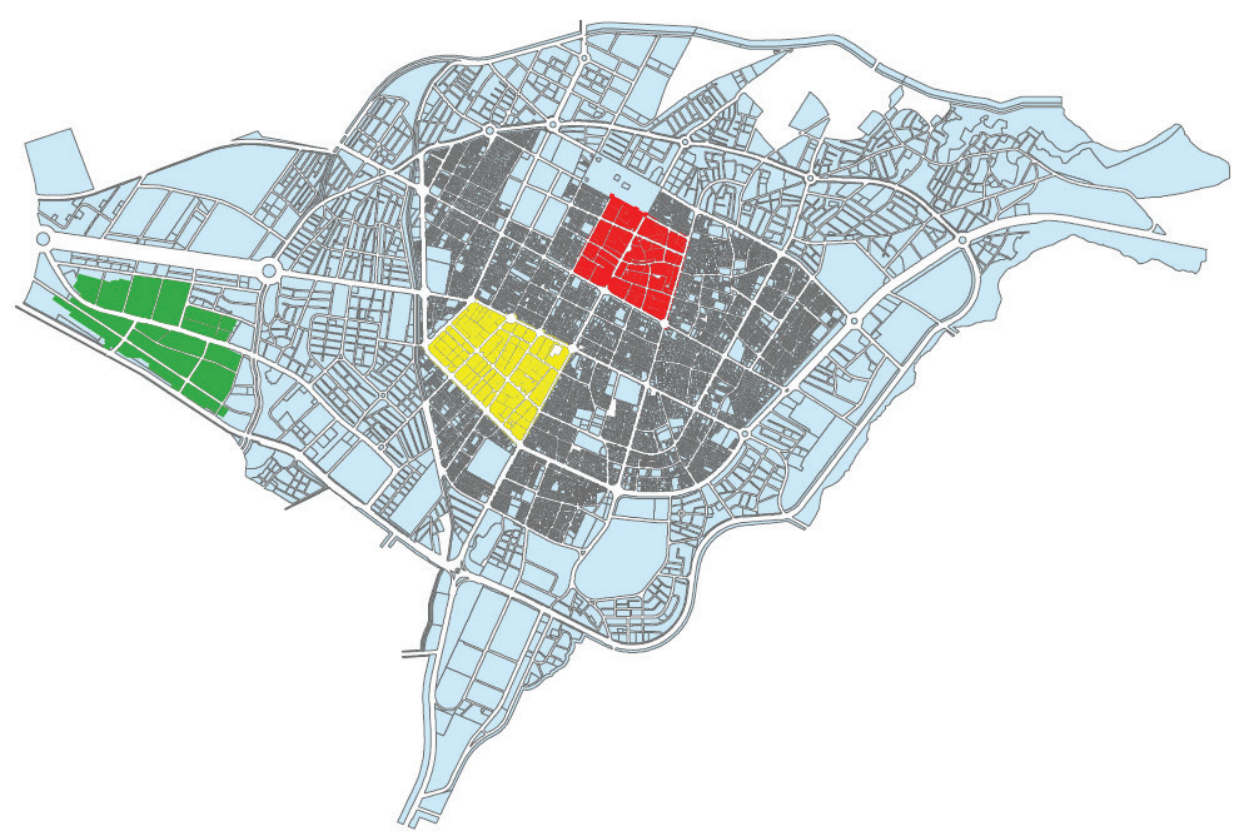

Figure 4. Introducing the studied districts (source: authors)

Table 2. Area of the uses in the three studied regions (source: authors)

\begin{tabular}{|c|c|c|c|c|c|c|c|c|c|c|c|}
\hline $\begin{array}{c}\text { Use } \\
\text { District }\end{array}$ & 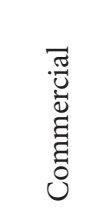 & 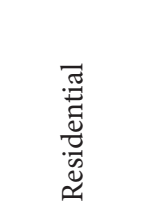 & 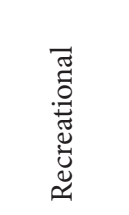 & 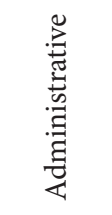 & 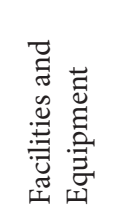 & 荨 & 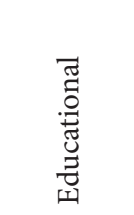 & 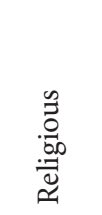 & 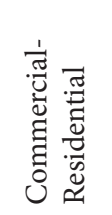 & 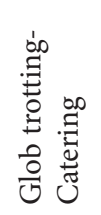 & 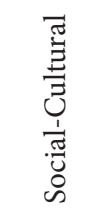 \\
\hline Old District & 45183.2 & 263391.2 & 4820.1 & 17281.9 & 14116.8 & 2224.5 & 10817.8 & 5510.9 & 21375.6 & 1890.1 & 1724.5 \\
\hline Medial District & 22094.2 & 383712.7 & 2186.03 & 5129.6 & 449.6 & 0 & 9142.5 & 3307.6 & 23822.1 & 1300.6 & 823.8 \\
\hline New District & 292.69 & 663046.59 & 75389.83 & 0 & 0 & 0 & 52480.25 & 0 & 0 & 0 & 1677.22 \\
\hline
\end{tabular}


Table 3. The extent of mixed land use in the three districts (source: authors)

\begin{tabular}{|l|c|}
\hline \multicolumn{1}{|c|}{ District } & Mixing Use \\
\hline Old & 0.5908 \\
\hline Medial & 0.2915 \\
\hline New & 0.2441 \\
\hline
\end{tabular}

\subsection{Calculating the obtained indexes from the questionnaire}

Given the fact that the questionnaire questions were analyzed based on the Likert spectrum, the average of the answers was ultimately calculated, the resulting data are shown in Table 4.

Table 4. Calculating the obtained index in each district (source: authors)

\begin{tabular}{|l|c|c|c|}
\hline $\begin{array}{l}\text { The Indexes Under Study } \\
\text { in the Questionnaire }\end{array}$ & $\begin{array}{c}\text { The old } \\
\text { district of } \\
\text { the city }\end{array}$ & $\begin{array}{c}\text { Medial } \\
\text { District }\end{array}$ & $\begin{array}{c}\text { New } \\
\text { District }\end{array}$ \\
\hline $\begin{array}{l}\text { Access to Public } \\
\text { Transportation }\end{array}$ & 3.27 & 2.51 & 2.75 \\
\hline $\begin{array}{l}\text { How to Access to Public } \\
\text { Transportation }\end{array}$ & 3.35 & 2.94 & 3.08 \\
\hline $\begin{array}{l}\text { Public Transportation } \\
\text { Quality }\end{array}$ & 2.55 & 2.08 & 2.51 \\
\hline Passageways Lightening & 3.02 & 3.12 & 2.88 \\
\hline Ruined Buildings & 3.02 & 2.07 & 1.48 \\
\hline No Disturbance & 2.97 & 4.01 & 4.02 \\
\hline Mixing Use & 3.61 & 3.4 & 2.82 \\
\hline Unpleasant Odor & 2.87 & 2.27 & 1.61 \\
\hline Rubbish Collection & 3.3 & 2.87 & 3.57 \\
\hline $\begin{array}{l}\text { Access to Urban } \\
\text { Furniture }\end{array}$ & 2.88 & 2.88 & 2.35 \\
\hline $\begin{array}{l}\text { Access to Sports and } \\
\text { Recreational Facilities }\end{array}$ & 2.3 & 2.42 & 2.15 \\
\hline $\begin{array}{l}\text { Failure to Dispose } \\
\text { Surface Water }\end{array}$ & 3.41 & 2.37 & 1.95 \\
\hline Enough Green Space & 3.24 & 3 & 1.98 \\
\hline Street Art Activities & 1.85 & 2.37 & 1.47 \\
\hline $\begin{array}{l}\text { Quality of Urban } \\
\text { Furniture }\end{array}$ & 2.92 & 2.8 & 1.78 \\
\hline Spending Leisure Time & 2.21 & 2.61 & 2.58 \\
\hline
\end{tabular}

\subsection{Calculating density indexes in the three studied districts}

The following table shows the obtained data from the study of the intersections density indexes, the length of the streets, the building density, and the population density in the three studied districts (Table 5):
Table 5. Calculation of the density indexes in the three studied districts (source: authors)

\begin{tabular}{|l|c|c|c|}
\hline \multicolumn{1}{|c|}{$\begin{array}{c}\text { District } \\
\text { Density }\end{array}$} & $\begin{array}{c}\text { Old } \\
\text { District }\end{array}$ & $\begin{array}{c}\text { Medial } \\
\text { District }\end{array}$ & $\begin{array}{c}\text { New } \\
\text { District }\end{array}$ \\
\hline Intersection density & 0.0000238 & 0.0000226 & 0.0000367 \\
\hline Street length density & 0.00915 & 0.01008 & 0.00903 \\
\hline Building density & 0.313 & 0.254 & 0.095 \\
\hline Population density & 0.0263 & 0.0149 & 0.0196 \\
\hline
\end{tabular}

\subsection{Calculating the indexes derived from the theory of space syntax in the three studied districts}

The table below shows the obtained data from the study of the parameters of the Space Syntax theory (both integration and connectivity) in the three studied districts (Table 6):

Table 6. The obtained data from the theory of space syntax in the three studied districts (source: authors)

\begin{tabular}{|l|c|c|c|}
\hline $\begin{array}{c}\text { District } \\
\text { Space Syntax }\end{array}$ & $\begin{array}{c}\text { Old } \\
\text { District }\end{array}$ & $\begin{array}{c}\text { Medial } \\
\text { District }\end{array}$ & $\begin{array}{c}\text { New } \\
\text { District }\end{array}$ \\
\hline Connectivity & 17.59 & 5.92 & 5.4 \\
\hline Integration & 1.95 & 1.87 & 1.69 \\
\hline
\end{tabular}

\subsection{Weighting the criteria through the ANP network analysis process}

At this stage, using the comments of ten experts for each region, using the ANP method and Super Decisions software, first, the relationship among the criteria was determined (this relationship could exist among the sub-criteria of one criterion with each other, or with sub-criteria of the other criteria, unidirectional or bidirectional). Then their paired comparison was done and the final weight was estimated.

An important point in calculating the weight of the criteria using the ANP method is the compatibility factor. This coefficient must be less than 0.1 to be accepted. In the present study, also the Compatibility Coefficient has been less than 0.1 in all the paired comparisons (Table 7).

\subsection{Using the TOPSIS method to achieve the superior walkable district}

In this study, the TOPSIS method was used for the final ranking of the districts in terms of walkability. The TOPSIS method has seven steps; the first one is the formation of a decision matrix (Table 8).

According to the above table, the decision-making matrix was created and after normalizing the data, the weighing operation was performed on a normalized matrix. Then the positive and negative ideal solutions were determined. The table below shows the distance from the worst and best solution calculated by the formula below: 
Determining the distance between the $\mathrm{i}$-th alternative from the ideal alternative (the highest performance of each indicator), which is represented by $\left(\mathrm{A}^{*}\right)$.

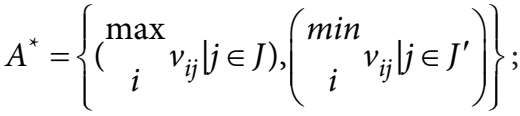

$$
\begin{aligned}
& A^{*}=\left\{v_{1}^{*}, v_{2}^{*}, \ldots, v_{n}^{*}\right\} \text {. }
\end{aligned}
$$

- Determining the distance between the i-th minimum alternative (the lowest performance of each indicator), which is represented by $\left(\mathrm{A}^{-}\right)$.

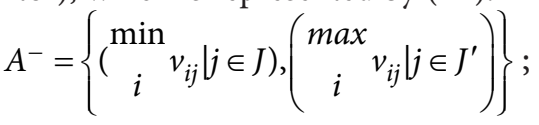

$$
\begin{aligned}
& A^{-}=\left\{v_{1}^{-}, v_{2}^{-}, \ldots, v_{n}^{-}\right\} \text {. }
\end{aligned}
$$

In the above equation, $v_{i j}$ equals the product of the standard values of each index in its own weights.

\begin{tabular}{|c|c|c|c|c|c|c|c|c|c|c|c|c|c|c|c|c|c|c|c|c|c|c|}
\hline 莺 & 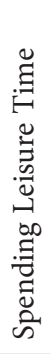 & 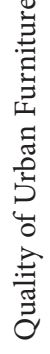 & 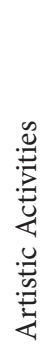 & 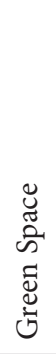 & 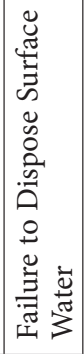 & 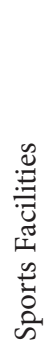 & 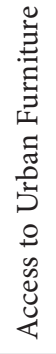 & 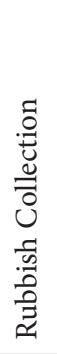 & 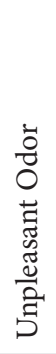 & 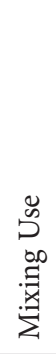 & 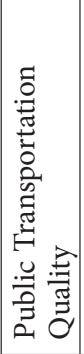 & 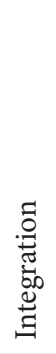 & 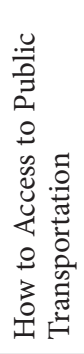 & 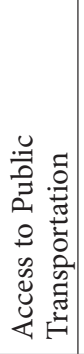 & 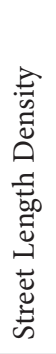 & 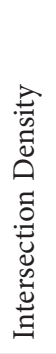 & 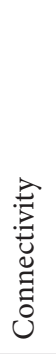 & 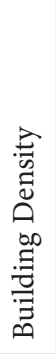 & 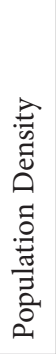 & 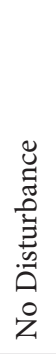 & 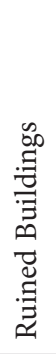 & 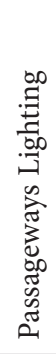 \\
\hline 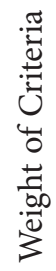 & $\begin{array}{l}\underset{\mathfrak{H}}{\stackrel{\Xi}{J}} \\
\stackrel{0}{0}\end{array}$ & $\begin{array}{l}0 \\
\stackrel{\infty}{0} \\
0 \\
0\end{array}$ & $\begin{array}{l}\frac{1}{\infty} \\
\stackrel{1}{1} \\
0 \\
0\end{array}$ & 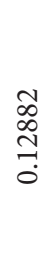 & 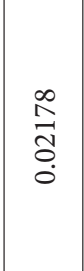 & \begin{tabular}{l}
$\vec{b}$ \\
\multirow{2}{0}{} \\
0 \\
0
\end{tabular} & 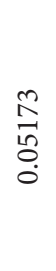 & $\begin{array}{l}\vec{\infty} \\
\stackrel{1}{5} \\
0 \\
0 \\
0\end{array}$ & $\begin{array}{l}\vec{\infty} \\
\infty \\
0 \\
0 \\
0\end{array}$ & 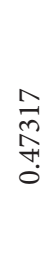 & 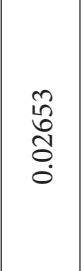 & 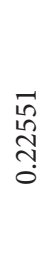 & $\begin{array}{l}\stackrel{\vec{\lambda}}{ } \\
\stackrel{0}{0} \\
\stackrel{0}{0}\end{array}$ & 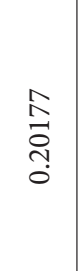 & $\begin{array}{l}\infty \\
0 \\
\stackrel{0}{0} \\
\dot{0} \\
0\end{array}$ & 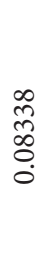 & 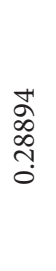 & \begin{tabular}{l}
+ \\
$\infty$ \\
$\infty$ \\
\multirow{+}{*}{} \\
$\stackrel{0}{0}$
\end{tabular} & $\begin{array}{l}0 \\
\vec{n} \\
\text { م⿱ } \\
0 \\
0\end{array}$ & 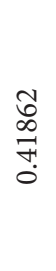 & 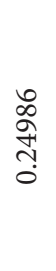 & $\begin{array}{l}\tilde{n} \\
m \\
\tilde{0} \\
0\end{array}$ \\
\hline
\end{tabular}

Table 7. Weighting the criteria through the ANP network analysis process (source: authors)

Table 8. Creating a decision matrix (source: authors)

\begin{tabular}{|l|c|c|c|c|c|}
\hline \multicolumn{1}{|c|}{ Matrix } & Old District & Medial District & New District & Type of Criteria & Weight of Criteria \\
\hline Connectivity & 17.59 & 5.92 & 5.4 & Positive & 0.288 \\
\hline Intersection Density & 0.0000238 & 0.0000226 & 0.0000367 & Positive & 0.083 \\
\hline Street Length Density & 0.0092 & 0.0101 & 0.009 & Positive & 0.091 \\
\hline Access to Public Transportation & 3.27 & 2.51 & 2.75 & Positive & 0.201 \\
\hline Modality of Access to Public Transportation & 3.35 & 2.94 & 3.08 & Positive & 0.082 \\
\hline Integration & 1.95 & 1.87 & 1.69 & Positive & 0.225 \\
\hline Public Transportation Quality & 2.55 & 2.08 & 2.51 & Positive & 0.026 \\
\hline Population Density & 0.0263 & 0.0149 & 0.0196 & Positive & 0.551 \\
\hline Building Density & 0.313 & 0.254 & 0.095 & Positive & 0.448 \\
\hline Street Lighting & 3.02 & 3.12 & 2.88 & Positive & 0.331 \\
\hline Ruined Buildings & 3.02 & 2.07 & 1.48 & Negative & 0.249 \\
\hline No Disturbance & 2.97 & 4.01 & 4.02 & Positive & 0.418 \\
\hline Mixed Land use & 3.61 & 3.4 & 2.82 & Positive & 0.473 \\
\hline Unpleasant Odor & 2.87 & 2.27 & 1.61 & Negative & 0.058 \\
\hline Rubbish Collection & 3.3 & 2.87 & 3.57 & & 0.074 \\
\hline Access to Urban Furniture & 2.88 & 2.88 & 2.35 & Positive & 0.051 \\
\hline Access to Sports and Recreational Facilities & 2.3 & 2.42 & 2.15 & Positive & 0.047 \\
\hline Failure to Dispose Surface Water & 3.41 & 2.37 & 1.95 & Negative & 0.021 \\
\hline Enough Green Space & 3.24 & 3 & 1.98 & Positive & 0.128 \\
\hline Street Art Activities & 1.85 & 2.37 & 1.47 & Positive & 0.017 \\
\hline Quality of Urban Furniture & 2.92 & 2.8 & 1.78 & Positive & 0.013 \\
\hline Spending Leisure Time & 2.21 & 2.61 & 2.58 & Positive & 0.112 \\
\hline & & & & & \\
\hline
\end{tabular}


Table 9. Determining the optimum solution (source: authors)

\begin{tabular}{|l|c|c|}
\hline \multicolumn{1}{|c|}{ Optimum Solution } & + & - \\
\hline Connectivity & 0.2621 & 0.0805 \\
\hline Intersection Density & 0.0619 & 0.0381 \\
\hline Street Length Density & 0.0562 & 0.0503 \\
\hline Access To Public Transportation & 0.1326 & 0.1018 \\
\hline $\begin{array}{l}\text { How To Access To Public } \\
\text { Transportation }\end{array}$ & 0.0507 & 0.0445 \\
\hline Integration & 0.1377 & 0.1193 \\
\hline Public Transportation Quality & 0.016 & 0.0131 \\
\hline Population Density & 0.4022 & 0.2279 \\
\hline Building Density & 0.3386 & 0.1028 \\
\hline Street Lighting & 0.1982 & 0.183 \\
\hline Ruined Buildings & 0.0933 & 0.1904 \\
\hline No Disturbance & 0.2622 & 0.1937 \\
\hline Mixing Use & 0.2993 & 0.2338 \\
\hline Unpleasant Odor & 0.0234 & 0.0416 \\
\hline Rubbish Collection & 0.0468 & 0.0376 \\
\hline Access to Urban Furniture & 0.0312 & 0.0255 \\
\hline $\begin{array}{l}\text { Access to Sports and Recreational } \\
\text { Facilities }\end{array}$ & 0.0286 & 0.0254 \\
\hline Failure to Dispose Surface Water & 0.0089 & 0.0156 \\
\hline Enough Green Space & 0.0857 & 0.0524 \\
\hline Street Art Activities & 0.012 & 0.0075 \\
\hline Quality of Urban Furniture & 0.0086 & 0.0052 \\
\hline Spending Leisure Time & 0.0682 & 0.0578 \\
\hline
\end{tabular}

Once the optimal solution for each criterion has been found (Table 9), the distance of each of the districts is determined from the ideal positive and negative solution. Table 10 represents the same.

Table 10. Determining the distance from the ideal positive and negative solutions (source: authors)

\begin{tabular}{|l|c|c|}
\hline \multicolumn{1}{|c|}{ Distance Size } & + & - \\
\hline Old District & 0.1232 & 0.3548 \\
\hline Medial District & 0.2612 & 0.2039 \\
\hline New District & 0.325 & 0.1432 \\
\hline
\end{tabular}

\section{Conclusions}

It was mentioned before that in the three old, medial, and new districts of Bojnourd, a region was investigated for the study of walkability. After examinations and calculations (according to Table 11), it was revealed that the highest walkability belongs to the old district while the medial and new districts are in lower ranks. Therefore, it can be concluded that in the city of Bojnourd and with the expansion of rural suburbs, getting closer to the city center increases the interest of citizens in walking. On the contrary, closer to the countryside, although the structure of the district is new and planned, the residents are much more reluctant to walk. This can be a warning to new urban planners and designers, and shows the need for more attention to green space, diverse applications, safe and fast access to public transportation, the design of attractive outdoor spaces for pedestrians to spend leisure time, etc.

Table 11. Ranking districts in terms of walkability (source: authors)

\begin{tabular}{|c|c|}
\hline Result & Coefficient of Proximity \\
\hline Old District & 0.7423 \\
\hline Medial District & 0.4385 \\
\hline New District & 0.3509 \\
\hline
\end{tabular}

Since population density, mixing use, building density, and non-disturbance have respectively the highest weights in the ANP method, therefore the preliminary of a walkable environment is the need for security in the districts. Two parameters of population density and density of buildings have increased social visibility in different places, as well as short trips in neighborhoods and districts and consequently social security. On the other hand, non-disturbance is also an important factor in maintaining social security. Alongside the social security index, mixed land use is another important factor in increasing the walkability in districts. Observing these points can lead to an increase in walkability in districts with less than the minimum record, which need to promote this important factor.

\section{References}

Brandstaetter, C., Alan, G., \& Evgenikos, P. (2010). Traffic safety basic facts pedestrians. Directorate - General for Mobility and Transport, 1-22.

Chapman, D. (2004). Creating neighborhoods and places in the built environment. Taylor \& Francis. https://doi.org/10.4324/9780203362341

Dettlafe, W. (2014). Space syntax analysis - methodology of understanding the space. PhD Interdisciplinary Journal, 283-329.

Ewing, R., Handy, S., Brownson, R., Clemente, O., \& Winston, E. (2006). Identifying and measuring urban design qualities related to walkability. Journal of Physical Activity and Health, 3(Suppl 1), S223-S240. https://doi.org/10.1123/jpah.3.s1.s223

Haeri, M. (1992). The color of losing the historic city in the colorless history of urban growth. Abadi Journal, 2(6) (in Farsi).

Hung, W. T., \& Manandhar, A., \& Ranasinghege, S. A. (2010). A walkability survey in Hong Kong. In TRANSED 2010: 12th International Conference on Mobility and Transport for Elderly and Disabled Persons, Hong Kong, China.

Iranian Statistical Center. (2016). https://www.amar.org.ir/

Lee, Y., \& Wu, W. (2005). Development strategies for competency models. International Trade Department, Ta Hwa Institute of Technology, Taiwan.

Litman, T. A. (2017). Economic value of walkability. Victoria Transport Policy Institute. https://www.vtpi.org/

Lwin, K., \& Murayama, Y. (2010). Modelling of urban green space walkability: Eco-friendly walk score calculator. Computers, Environment and Urban Systems, 35, 408-420. https://doi.org/10.1016/j.compenvurbsys.2011.05.002

Martin, A. (2006). Factors influencing pedestrian safety: a literature review. In Pedestrian Attitudes, Behaviour and Road 
Safety Client: Ben Johnson, London Road Safety Unit, Transport for London. Copyright TRL Limited February.

Moeini, M. M. (2007). Pedestrian behavior in relation to residential and commercial locations case study: district 6 of Tehran municipality. Journal of Fine Arts, 32, 15-26.

Mohammadi, A., \& Hajizadeh, M. I. (2016). Measurement and ranking of urban neighborhoods in pedestrian city indicators (Case study: Ardabil city). Journal of Urban Research and Planning, 3(26), 131-152.

Naqsh,e Jahan-Pars consulting engineer. (2011). Bojnurd comprehensive plan. Ministry Road and Urban development.

Nasiri, E. (2012). Design and control strategies of pedestrian urban spaces. Geography Educating Journal of Roshd, 25(4), 13-19.

Pourmohammadi, M., \& Koushaneh, R. (2014). Evaluation and analysis of urban public spaces using Topsis model (Case study: Tabriz city). Urban and Regional Studies and Researches, 5(17), 37-52.

Rafieian, M., \& Sedighi, E., \& PourMohammadi, M. (2012). Feasibility of enhancing environmental quality by making urban axes walkable (Case study: Eram st. of Qom city). Urban and Regional Studies and Researches, 3(11), 41-56.

Raja, A., Raja, N., \& Zahari, R. (2013). Perceptions of the urban walking environments. Asia Pacific International Conference on Envi-
ronment-Behaviour Studies. Procedia - Social and Behavioral Sciences, 105, 589-597. https://doi.org/10.1016/j.sbspro.2013.11.062

Rattan, A., Campese, A., \& Eden, Ch. (2012). Modelling walkability, regional municipality of Halton, Ontario, Canada (pp. 30-33). Esri.com

SabzaliYamghani, A., \& Alesheikh, A. (2015). Development and evaluation of a walkability index (Case study: Neighborhoods of Qom city). ISC Journal of Cartographic Science and Technology, 5(1), 159-174.

Shamsuddin, S., Abu Hassan, N. R., Ilani, B., \& Siti, F. (2012). Walkable environment in increasing the liveability of a city. ASEAN Conference on Environment-Behaviour Studies (pp. 167-178). Bangkok, Thailand. https://doi.org/10.1016/j.sbspro.2012.08.025

Soltani, A., \& Pirouzi, R. (2013). Surveying pedestrian capability in cultural-historical axes [Case study: Hafiz axe of Shiraz]. City and Native Architecture Journal, 3, 65-77 (in Farsi).

Waldock, R. (2012). Designing for pedestrians: guidelines. Department of Transport. http://www.transport.wa.gov. au/ media Files/WALK_P_Walkability_Audit_Tool

Ziari, K., ParsiPour, H., \& Aliabadi, N. (2012). Mid era fabric of cities: A capacity towards compact city pattern (Case study: Bojnourd city). Journal of Geography and Regional Development, 10(19), 215-236. 